\title{
Colaboración internacional en las ciencias sociales y humanidades: inclusión, participación e integración
}

\author{
International collaboration in social sciences and humanities: \\ inclusion, participation and integration
}

Eduardo Aguado-López / eal123@gmail.com
orcid.org/0000-0002-4322-9556

Arianna Becerril-García / arianna.becerril@gmail.com

orcid.org/0000-0003-0278-8295

Sheila Godínez-Larios / sheilaredalyc@gmail.com

Universidad Autónoma del Estado de México, México

\begin{abstract}
The generation of scientific knowledge now responds to a primordially collaborative schema that gradually transitions from the institutional to the international. Social Sciences and Humanities in Latin America have joined this trend, however, their international collaboration has been oriented toward an asymmetric schema in terms of inclusion: only one sector of countries has joined, while another significant group remains isolated; participation: interactions are concentrated by countries with more written science; and integration: it tends to a north-south type of collaboration. The analysis of Latin American international scientific dialogue considers the period of 2005-2015 and it is used redalyc. org database for its representation in the disciplinary and regional, starting from a universe of 10,332 interactions among researchers in the region. It is concluded that these trends of international collaboration are emerging as effects of the current system of communication and evaluation of science.
\end{abstract}

Key words: international collaboration, social sciences, arts, humanities, Latin America.

Resumen: La generación de conocimiento científico responde, en la actualidad, a un esquema primordialmente colaborativo que transita gradualmente de lo institucional hacia lo internacional. Las ciencias sociales y artes y humanidades latinoamericanas se adhieren a esta tendencia; sin embargo, su colaboración internacional se ha orientado a un esquema asimétrico en términos de inclusión: sólo un sector de países se ha sumado, mientras que otro grupo significativo permanece aislado; participación: las interacciones están concentradas por los países con más ciencia escrita; e integración: se tiende a una colaboración de tipo norte-sur. El análisis que se presenta del diálogo científico latinoamericano internacional considera el periodo 2005-2015 y se recurre a redalyc.org por su representatividad en lo disciplinar y regional, partiendo de un universo de 10,332 interacciones de investigadores de la región. Se concluye que dichas tendencias de colaboración internacional se desprenden como efectos del actual sistema de comunicación y evaluación de la ciencia.

Palabras clave: colaboración internacional, ciencias sociales, arte, humanidades, Latinoamérica. 


\section{Introducción}

En la configuración del vigente mapa científico global destaca la confluencia de dos fenómenos. Por un lado, se observa la multiplicación de la producción científica mundial, en la cual los núcleos europeos y anglosajones han cedido terreno a la creciente contribución de regiones como Asia, Oriente Medio y Latinoamérica (Hernández, 2014: 9-10; Science-Metrix, 2010:7). No obstante, tal tendencia resalta que estas regiones no han conseguido una presencia significativa en el mainstream, ante lo cual resultan de vital importancia los circuitos regionales de comunicación de los que tienen control.

En segundo lugar, se aprecia un incremento de la colaboración en distintos ámbitos y de diverso alcance entre los actores involucrados en la generación y promoción de la ciencia. Así, en las últimas décadas se advierte, por ejemplo, un incremento de la movilidad internacional de estudiantes a nivel superior y posgrado en Latinoamérica; así como de especialistas, movilidad que toma la forma de emigración permanente, periodos sabáticos, conferencias, participación en programas de posgrado y estadías cortas de investigación; ambas, resultado de una cooperación internacional creciente entre universidades, instituciones de educación superior, centros de investigación y gobiernos tanto regionales como de otros puntos geográficos (Didou, 2006: 5; Vessuri, 2009: 199).

Una de las principales expresiones de la colaboración en la práctica científica la representa la coautoría, práctica común en las ciencias naturales y exactas $(\mathrm{CNyE})$, que se ha trasladado en las últimas décadas a las ciencias sociales (CS) y las artes y humanidades $(\mathrm{AyH})$, incluida la comunidad de Latinoamérica (Aguado-López y Becerril-García, 2016: 4-9).

La colaboración, en específico la de corte internacional, es un tema extensamente estudiado desde las relaciones que se establecen a través de la coautoría en artículos científicos; en su análisis se ha puesto énfasis de manera primordial en la variabilidad por país de la capacidad para establecer interacciones (a través de coeficientes de colaboración externa) y en los nexos establecidos por las instituciones centrales y los países con mayor producción científica, con fundamento en información proveída por bases de datos de corriente principal, ejemplo: Web of Science y Scopus.

En tales estudios los resultados muestran una constante: redes de colaboración sólidas al interior del norte y en menor medida del norte con el sur; y en los casos de colaboración al interior de Latinoamérica, un crecimiento de la producción en coautoría, cuyos productos se publican en su mayoría en inglés (Mosbah-Natanson y Gingras, 2013: 626-646; Frenken 
et al., 2010: 148-153; Russell et al., 2007: 180-198; Ruiz y Russell, 2016: 11-32; Comisión Europea y Science-Metrix, 2015: 9-15; Mêgnigbêto, 2013; Varun y Bhattacharya, 2014; Calvert, 2017: 11-13).

La mayor presencia del sur global en la producción científica mundial y el incremento de la colaboración internacional son características sobresalientes de la práctica científica actual. Esto tiene lugar, sin embargo, en un sistema de comunicación y evaluación que está modificando el sentido de la investigación, la publicación y el propio diálogo entre los investigadores, el cual se caracteriza por una comunicación direccionada principalmente al norte; mientras que la integración del sur global permanece como una tarea pendiente.

Tras observar el avance regional en términos de colaboración, sus retos pendientes y la falta de estudios basados en universos de información representativos respecto al idioma, áreas de conocimiento y región, se emprende un análisis de las tendencias que sigue el diálogo científico internacional en las comunidades latinoamericanas y caribeñas de CS y de AyH. En dicho análisis se toma como referente el comportamiento de los artículos en coautoría externa (artículos en coautoría cuyos autores están adscritos a diversos países) de investigadores latinoamericanos y caribeños, publicados en revistas indizadas por redalyc.org.

Con el objetivo de plantear una hoja de ruta del diálogo científico global de Latinoamérica, el fenómeno colaborativo se aborda específicamente desde tres aristas:

- Inclusión: identificar a los países de la región que se han adherido al diálogo y a los países que permanecen aislados de la conversación internacional.

- Participación: determinar en qué medida está participando cada país de Latinoamérica y el Caribe en el diálogo.

- Integración: reconocer con qué países los investigadores latinoamericanos y caribeños están estableciendo vínculos.

A su vez, la estructura que sigue el presente escrito es la siguiente: en el segundo apartado se analiza el sistema actual de comunicación de la ciencia, los mecanismos de evaluación al desempeño de investigadores, y los impactos que en conjunto han tenido en el sentido de la investigación, la publicación y, en especial, en el diálogo entre investigadores. En el tercer apartado se caracterizan la metodología y los datos que sustentaron el análisis de las tendencias de colaboración internacional en las CS y las $\mathrm{AyH}$ latinoamericanas. En el cuarto apartado se muestran los hallazgos de dicho análisis. Finalmente, en el quinto apartado se despliega una serie de supuestos 
a manera de conclusión del estado actual y prospectivas del diálogo científico del sur global.

El presente escrito parte de una concepción de la colaboración como una práctica compleja que involucra múltiples actores en tareas diversas; se colabora en todos los momentos de la práctica científica y esta cooperación puede tener distintos alcances. De tal forma se reconoce que colaboración y coautoría son nociones distintas, que la coautoría no es el único indicador para dar cuenta del fenómeno colaborativo y que en su análisis se dejan fuera otras variables de igual importancia (González y Gómez, 2014: 3).

Sin embargo, la coautoría representa la evidencia más sólida para dar cuenta de la colaboración, y en el caso de la información proveída por redalyc.org, se trata, además, de un universo de información novedoso y pertinente para caracterizar un fenómeno, áreas temáticas y región poco estudiados. La diferencia estriba en que los estudios existentes analizaron a Latinoamérica a partir del Web of Science o Scopus, mientras aquí se toma una base regional más representativa.

\section{Participamos y colaboramos más: asimetrías en las buenas noticias}

La globalización se ha traducido en un objetivo estandarizado en la práctica científica, área en la cual se busca que la circulación del conocimiento generado en todas las regiones, norte o sur, tenga una visibilidad global. Buscamos ser visibles globalmente y esto lo hemos traducido en tener una presencia en las bases de datos de corriente principal: las revistas han de estar indizadas por dichas bases de datos y los investigadores han de publicar en tales revistas para que sus contribuciones no sólo tengan una visibilidad internacional (lo cual no necesariamente tiene el resultado esperado), sino que se consideren de calidad.

Es decir, a las bases de datos comerciales se les ha cedido un doble papel: certificadoras de la calidad (no necesariamente garantizándola) y diseminadoras del conocimiento científico (conocimiento al que únicamente pueden acceder aquellos que pueden pagar, incluidos los propios autores) (Santos, 2013: 16-17).

En este escenario, las entidades oficiales de impulso a la ciencia y tecnología (universidades, instituciones de educación superior, consejos nacionales de ciencia y tecnología, centros de investigación) tienen un rol principal, pues a través de programas de fomento y evaluación a la práctica científica promueven la publicación de artículos científicos, priorizando a las revistas mejor posicionadas por los rankings internacionales, los cuales toman como medida el Factor de Impacto. 
Esto tiene a su vez como telón de fondo una subrepresentación de Latinoamérica, sobre todo en cuanto a las $\mathrm{CS}$ y las $\mathrm{AyH}$, en la corriente principal y una calificación menor de las revistas de esta región. Ejemplo de lo anterior es que en el Journal Citation Reports (JCR), edición 2015, las revistas latinoamericanas se distribuyeron de la siguiente forma según su impacto: el $18.8 \%$ se ubicó en el cuartil 1, el $4.7 \%$ en el cuartil 2 , el $14.1 \%$ en el cuartil 3, y el grupo más numeroso, el $62.3 \%$, se ubicó en el cuartil 4 .

La búsqueda de la visibilidad global y de la calidad a partir de la presencia de los actores en los circuitos del mainstream muestra un punto sensible a la pertinencia local de la investigación, pues al buscar figurar en dichas bases se adoptan los temas que se discuten en las revistas de este circuito, sus metodologías, su idioma (inglés), además del establecimiento de un diálogo con los referentes que participan en esta agenda, a través de las citas.

Se trata de una influencia que no toma la forma de un imperialismo manifestado en la aculturación total o imposición de ideas, sino de una dependencia académica en tanto que adoptamos y reproducimos las pautas de publicación y comunicación de los circuitos centrales (Gómez-Morales, 2015: 297). El escenario donde se desenvuelve la empresa científica se ha tornado complejo y se hace frente a una tensión entre lo global y lo local, la autonomía y la heteronomía; nociones que coexisten en las prácticas actuales de generación y circulación del conocimiento (Beigel, 2015 y 2013: 112).

La presencia de los actores regionales en la corriente principal ha pasado de ser un indicador a un objetivo en sí mismo; se ha confundido el "no participar" en este circuito con "no hacer" y se han perdido de vista mecanismos de evaluación y fomento que permitan observar lo que se busca con la aportación de conocimiento científico: una incidencia en los contextos sociales, económicos y políticos locales; es decir, un impacto social, no un Factor de Impacto.

De igual forma, este paradigma de evaluación y comunicación representa una paradoja para el contexto regional en tanto que Latinoamérica ha construido un ecosistema de Acceso Abierto (AA), impulsado principalmente por entidades gubernamentales, las cuales financian la generación de conocimiento científico, las revistas arbitradas donde dicho conocimiento se publica y las bases de datos en AA (ejemplo SciELO, Redalyc, CLACSO, Latindex, La Referencia) que alojan el conocimiento generado. La paradoja consiste en buscar en la corriente principal el referente de visibilidad internacional y calidad, y contar paralelamente con un ecosistema sólido de AA único en el mundo, del cual se ha prescindido en la evaluación de la ciencia generada en la región. 
Con el movimiento de AA se buscaba un contrapeso a las reglas de juego de los principales núcleos científicos y los sistemas de comunicación creados por éstos; sin embargo, no se ha reconocido a las bases regionales de AA como plataformas legítimas y válidas en la evaluación del desempeño científico, pese a estar cumpliendo su función primordial: maximizar la audiencia del conocimiento científico a círculos ajenos a los académicos, aumentar el impacto de la ciencia, investigadores e instituciones regionales; y posibilitar el intercambio científico entre especialistas, propiciando un diálogo multicultural, multidisciplinario y global (Marin et al., 2015: 77; Banerjee et al., 2015: 14-27).

Ejemplo de lo anterior es que las revistas mexicanas sumaron 85,215,667 consultas entre 2014 y 2015 en SciELO y redalyc.org (Aguado-López et al., 2016: 6). En este orden de ideas, la noción de "ciencia perdida del tercer mundo" (Gibbs, 1995: 92-99) resulta operante exclusivamente en los circuitos que la excluyen, pues en el contexto latinoamericano la producción y proyectos editoriales se multiplican y circulan principalmente en AA. En términos de generación y circulación del conocimiento científico, cabe retomar críticamente las experiencias de los países que persiguen la presencia en el mainstream y su agenda como referentes de visibilidad internacional y calidad; y reconocer que éstos no son los únicos senderos que el sur puede seguir (Orellano, 2015: 51).

El esquema actual de evaluación y comunicación que se promueve desde las políticas de ciencia y tecnología ha impactado, a su vez, a la colaboración entre investigadores de dos formas principalmente: en sus motivaciones y su estructura. Entre los factores que motivan a la colaboración es posible ubicar uno reciente: la exigencia de productividad que ejercen dichos mecanismos institucionales de evaluación, los cuales han conducido a los investigadores a modificar sus prácticas en torno a la generación de aportes científicos, adoptando la asociación como una nueva forma de trabajo.

Las comunidades científicas están modificando sus prácticas y con ello su cultura académica, dada la necesidad de responder positivamente a los estándares institucionales de evaluación; así, la colaboración se reconoce no sólo como una práctica que posibilita el acceso y eficiencia de recursos de investigación de diverso tipo, permite hacer el trabajo más operativo, posibilita un abordaje multi, inter o transdisciplinario, sino como una estrategia que potencia la productividad de los investigadores y les permite subsistir y escalar institucionalmente (Fanelli y Larivière, 2016: 9).

Respecto a la estructura de la colaboración, destaca que ésta tiene un peso desequilibrado entre las regiones "emergentes" y los circuitos científicos 
consagrados; la tónica mundial del diálogo en la ciencia es la dirección nortenorte, en menor medida norte-sur, y pocas veces sur-sur (Leydesdorff et al., 2013: 90-93; Frenken et al., 2010: 149-50; Beigel, 2013: 118-119). En términos de integración regional, esto representa un obstáculo, pues en la medida en que no se propicia la inclusión de todos los países de la región al diálogo y se prioriza la comunicación con el norte, se pierden oportunidades de superar problemáticas compartidas, de contribuir a las diversas disciplinas con abordajes metodológicos novedosos, y de proponer nuevas categorías teórico-conceptuales útiles y apropiadas en el análisis de las problemáticas locales.

En las implicaciones y significados de la coautoría debe considerarse que ésta es, en principio, comunicación e intercambio de ideas alrededor de problemáticas compartidas, en una búsqueda permanente de internacionalización; ambas vías en el análisis y/o de intervención nutridas por el intercambio de ideas, trayectorias y marcas culturales de las partes involucradas, en beneficio mutuo y del contexto que comparten (Hernández, 2016). Sin embargo, en los casos de colaboración norte-sur se observa una tendencia de integración subordinada del sur, con posibilidades estrechas de negociación (Kreimer, 2013: 443-449).

La participación de todos los actores latinoamericanos y caribeños en un diálogo científico incluyente es uno de los pilares sobre los cuales ha de descansar la superación integral a las múltiples desigualdades que aquejan a la región, aspecto en el cual las políticas científicas latinoamericanas deben concentrarse, pues son marcos que proveen objetivos y condiciones que favorecen o dificultan los procesos que conducen a la cooperación científico-tecnológica internacional (Paz, 2015: 2).

La inclusión de las comunidades científicas de todos los países regionales en un diálogo científico, así como del sur global, debe pensarse como uno de los objetivos centrales de las políticas de ciencia y tecnología regionales. Así, ante una brecha en la capacidad de dialogar y construir vínculos de alcance internacional y ante un diálogo direccionado hacia los principales núcleos científicos, la integración del sur se muestra como una meta en orden de consolidar las estrategias regionales de crecimiento económico y desarrollo institucional y social (Russell et al., 2007: 195-196).

En el caso latinoamericano, la exclusión, la pobreza, violencia, conciliación, migración y paz son algunos de los temas más relevantes, los cuales, en el contexto actual de dependencia académica, merecen un abordaje desde el sur, con referentes académicos que partan del contexto local en sus aportaciones y cuyos productos circulen en los circuitos a los cuales la sociedad latinoamericana tiene acceso. 


\section{Método y universo de estudio}

Se recurrió a la base de datos de redalyc.org, pues se considera un universo de información sólido y representativo en lo disciplinar y lo regional: tiene en su acervo 843 revistas de CS y de $\mathrm{AyH}$, cuya producción cuenta con datos normalizados a partir de 2005 y en la cual los artículos de autores latinoamericanos representan el $76.0 \%$.

El estudio de las interacciones de investigadores latinoamericanos con extranjeros (entre latinoamericanos así como de éstos con investigadores de otras regiones geográficas) es la variable sobre la cual descansa el presente escrito; en ello se desagregó por país la cantidad de artículos producidos en colaboración externa (artículos en coautoría que tienen autores de distintos países).

Así, por ejemplo, en el caso de un artículo con autores de tres países, se cuenta un artículo para cada país; mientras que en el caso de un artículo con dos autores del mismo país y un autor de un país distinto, se cuenta únicamente un artículo para el primer país y un artículo para el segundo (es decir, solamente un artículo por país, pese a que haya participado más de un autor del mismo país). Desagregados de tal forma los artículos científicos, conviene observarlos como interacciones internacionales que han establecido los investigadores latinoamericanos y caribeños, las cuales ascienden a 10,332 y constituyen el universo de estudio del presente análisis, el cual, a su vez, considera el periodo 2005-2015.

En la Figura $1^{1}$ se muestra la composición del universo de estudio por áreas de conocimiento, se especifica la cantidad de instituciones y países que participaron en las interacciones internacionales, la cantidad de revistas en que se publicaron los artículos científicos resultantes de dichas interacciones, así como la cantidad de disciplinas donde se registró colaboración internacional (en el caso de CS todas las disciplinas del área registran colaboración internacional; en el caso de $\mathrm{AyH}$ fueron cinco disciplinas de seis). Cabe mencionar que en el análisis se sigue la clasificación por disciplinas propuesta por Redalyc.org, la cual es definida a partir de la información proporcionada por las propias revistas.

1 Las tablas y la figura se encuentran en el Anexo, al final del presente artículo (Nota del editor). 
Eduardo Aguado-López, Arianna Becerril-García y Sheila Godínez-Larios. Colaboración internacional en las ciencias sociales y humanidades: inclusión, participación e integración

\section{El diálogo internacional de las CS y las AyH latinoamericanas}

Las CS latinoamericanas están transitando a un esquema de trabajo sobre todo colaborativo y gradualmente van dejando de lado el trabajo en solitario; por ejemplo, los artículos en coautoría crecieron 19.2 puntos porcentuales entre 2005 y 2014 y tuvieron un crecimiento promedio anual que superó siete veces el de los artículos de un autor. En esta tendencia el cambio central es que se pasa de una coautoría institucional a una de alcance nacional e internacional (Aguado-López y Becerril-García, 2016: 6).

Las CS de Latinoamérica están construyendo redes de colaboración que tienden hacia la exogeneidad; no obstante, se observa una inclusión desigual por países en este diálogo científico internacional: en el área de CS sólo 26 de los 41 Estados de Latinoamérica y el Caribe que considera el presente estudio han participado del diálogo en al menos una ocasión entre 2005 y 2015, es decir, el 63.4\% de los países de la región. ${ }^{2}$

Este escenario se agrava al observar que la no participación de algunos países en el diálogo internacional se debe a que no cuentan con producción científica. En la Figura 2 se representa tanto la inclusión de los países en la red de colaboración internacional como a los países que no cuentan con artículos científicos, en las áreas de CS y de $\mathrm{AyH}$.

A su vez, en el desempeño de los países que se han incluido en el diálogo internacional de CS, se observa que la mayoría se ha desenvuelto de forma positiva, a partir de la tasa de crecimiento media acumulada (TCMA) de las interacciones por país. Con la finalidad de comparar objetivamente el desenvolvimiento de cada uno, se agruparon de acuerdo con la cantidad de artículos publicados por sus investigadores, y resultaron de tal forma cuatro grupos: de actividad consolidada, alta, media e inicial.

Destacan Colombia, Argentina, Ecuador y Nicaragua como los países con el comportamiento más dinámico en torno al establecimiento de vínculos internacionales, en sus respectivos grupos. Asimismo, resalta el caso de Belice, Bahamas, Barbados y Trinidad y Tobago, que muestran un ritmo de crecimiento nulo o negativo, síntoma de la poca inclusión que han tenido en el diálogo científico global (véase la Figura 3).

2 En la determinación de los países considerados en el presente análisis se tomó como referencia el reconocimiento de países que hace la CEPAL en los perfiles de la región en torno a los Objetivos de Desarrollo del Milenio, donde se incluyen 40 países. A esta clasificación se agregó Puerto Rico como el país número 41, pese a que la CEPAL no lo reconoce como Estado soberano. 
La cantidad de vínculos científicos internacionales se ha incrementado significativamente en los últimos años. En 2005 se registraron 409 interacciones en el área de CS, mientras que en 2015 ascendieron a 1,600; lo cual implica un crecimiento de $291.2 \%$ (véase la Figura 4). En ello se observa que la participación de los países que se han integrado al diálogo sigue una dinámica asimétrica. Se registró en 2005 la participación de 16 países, no obstante México y Brasil concentraron prácticamente la mitad de las interacciones internacionales de la región, y el rango de participación por país se ubicó entre el $24.4 \%$ y el $0.2 \%$.

Por su parte, 2015 permite apreciar que la participación por país se polarizó: 22 países participaron; sin embargo, Brasil pasó a concentrar poco más de la cuarta parte de los vínculos internacionales establecidos por Latinoamérica, mientras que la participación de 13 países no superó el 2.0\% (véase la Figura 4).

Respecto a la dirección de la colaboración internacional, se observa en las CS una tendencia a colaborar preeminentemente con el norte global. En la Figura 5 se señala la cantidad de interacciones que cada país estableció en 2005 y la cantidad de países involucrados; asimismo, se representa la medida en que Latinoamérica colaboró con cada país. Se observa que de los 16 países que registraron colaboración externa en 2005, 10 muestran interacciones principalmente con el norte global, en específico con España (es el caso de México, Chile, Venezuela, Cuba, Perú y Ecuador), Estados Unidos (Brasil, Colombia y Costa Rica) y Bélgica (Nicaragua).

$\mathrm{La}$ inclinación por establecer vínculos sobre todo con una entidad, en especial con España y Estados Unidos, se polariza gradualmente y compone un escenario que muestra una baja integración regional y con el sur global en general. En 2015 se observa, por ejemplo, que de los 22 países que registraron colaboración externa, 8 interactuaron principalmente con España (México, Colombia, Chile, Argentina, Ecuador, Venezuela, Costa Rica y República Dominicana), 1 con Portugal (Brasil) y 1 con Estados Unidos (Puerto Rico).

Se observa en las CS latinoamericanas una tendencia por concentrar sus vínculos en pocas entidades, sobre todo del norte, en oposición a una colaboración internacional diversa y heterogénea que denote una integración del sur. La colaboración tipo norte-sur se trata de un comportamiento que no es propio únicamente de Latinoamérica, sino de las CS del sur global.

Así, Latinoamérica, por ejemplo, registró en el periodo 2000-2009 un total de 1,960 artículos en coautoría externa en el Social Science Citation Index de Thomson Reuters, distribuidos entre Norteamérica (61.7\%) y Europa (42.2\%); mientras que África registró 1,777 artículos en coautoría, 
distribuidos entre Norteamérica (46.5\%), Europa (55.7\%) y Asia (7.0\%); situación que para las regiones consagradas en términos de producción científica, como Europa y Norteamérica, se traduce en un diálogo más diversificado, pero de igual forma dirigido al norte (Mosbah-Natanson y Gingras, 2013: 636).

En el análisis del acumulado de las interacciones de CS establecidas por los países de Latinoamérica se observa a partir de Redalyc.org que la interacción con entidades como Estados Unidos, España y el resto de Europa concentra un porcentaje significativo que se asemeja a los vínculos establecidos con Latinoamérica en su conjunto y en algunos casos la superan; un escenario que obstaculiza una integración regional y con el sur global. Destaca Brasil, cuyas interacciones en el periodo 2005-2015 con Europa superan la colaboración con los países de Latinoamérica; asimismo, el caso de México, cuyas interacciones con España y Latinoamérica en conjunto tienen un peso relativo semejante (véase la Figura 6).

Por su parte, en las AyH latinoamericanas, los artículos en coautoría crecieron 10.3 puntos porcentuales entre 2005 y 2014, y su crecimiento promedio anual prácticamente triplicó el de los artículos de un autor. En esta área de conocimiento el cambio central es que se pasa de una coautoría institucional a una de alcance nacional e internacional (Aguado-López y Becerril-García, 2016: 6-10).

La colaboración avanza en las AyH latinoamericanas y tiende hacia un diálogo internacional; sin embargo, en esta tendencia están participando únicamente 17 países de la región; es decir, el 41.4\% de las naciones. A su vez, en los países que se han incluido en el diálogo se observa un comportamiento contrastante: positivo en 11 , mientras que 6 se comportan a la baja o con un crecimiento nulo, tomando como referencia la TCMA de las interacciones internacionales establecidas por país.

Con la finalidad de comparar el desempeño por país en este aspecto, se integraron grupos según la cantidad de artículos producidos por las distintas naciones, lo cual dio como resultado tres categorías: de actividad consolidada, alta y media. Resaltan México y Perú como los países con el comportamiento más dinámico al interior de sus respectivos grupos (véase la Figura 7).

Las interacciones internacionales en las $\mathrm{AyH}$ crecieron 516.6\% si se observan sólo los años de los extremos; se trata de un comportamiento positivo que, no obstante, encierra una participación asimétrica por país. Como se observa en la Figura 8, en 2005 el rango de participación por país se ubicó entre $25.0 \%$ y $8.3 \%$, mientras que en 2015 el rango se amplía y va de $23.0 \%$ a $1.3 \%$. Se aprecia que la dificultad por colaborar con pares del extranjero se 
acentúa para algunos países; en tanto que aquellos que ya interactuaban con especialistas del extranjero cobraron mayor protagonismo con el paso del tiempo.

En relación con el punto “¿quién colabora con quién?” en las AyH, se percibe al inicio del periodo de estudio un diálogo diversificado, tendencia que se modificaría dado un viraje hacia un diálogo dirigido principalmente a una entidad. Destaca que en esta área de conocimiento el diálogo se dirige hacia el sur, en especial hacia Latinoamérica (véase la Figura 9).

El análisis de las interacciones internacionales en conjunto (2005-2015) permite apreciar que en $\mathrm{AyH}$ no se observa un diálogo del tipo norte-sur en los estándares de las CS, sino una mayor integración con Latinoamérica, lo cual se refleja en que las interacciones latino-latino tienen un peso relativo significativamente mayor respecto al de otras regiones. Pese a lo anterior, cabe prestar atención al comportamiento de Brasil y Venezuela, países cuyas interacciones con Latinoamérica tienen un peso relativo cercano al de las interacciones con España, Portugal y el resto de Europa (véase la Figura 10).

\section{Conclusiones}

El sur global ha consolidado sus estructuras científicas, y su capacidad de diálogo se ha incrementado significativamente. Estas tendencias plausibles tienen lugar, sin embargo, en un sistema de comunicación y evaluación de la ciencia que ha propiciado distorsiones en el sentido de la investigación, la publicación y el diálogo entre los investigadores, cuyas motivaciones y estructura son atravesadas por una serie de asimetrías.

En las CS y las AyH latinoamericanas se observan sensibles deudas en torno a la inclusión por países, una participación diversificada y una integración regional y con el sur, las cuales debieran considerarse prioridades de la política científica de los países latinoamericanos y caribeños, en tanto que constituyen nodos vitales del desenvolvimiento regional y de la superación de problemáticas compartidas.

En la construcción de redes sólidas de colaboración científica, incluyentes, heterogéneas y diversificadas, el ecosistema de AA de Latinoamérica tendría un papel protagónico en tanto que proporciona parte de los insumos necesarios en una comunicación abierta, a través de la libre publicación de contribuciones y el libre acceso a la literatura. Pese a los retos pendientes, el acceso a la información científica ha sido cubierto; queda una tarea por realizar: su aprovechamiento en la construcción de vínculos científicos. 
Eduardo Aguado-López, Arianna Becerril-García y Sheila Godínez-Larios. Colaboración internacional en las ciencias sociales y humanidades: inclusión, participación e integración

\section{Referencias}

Aguado-López, Eduardo y Becerril-García, Arianna (2016), “¿Publicar o perecer? El caso de las ciencias sociales y las humanidades en Latinoamérica”, en Revista Española de Documentación Cientifica, vol. 39, núm. 4, España: CSIC. Disponible en: http:// dx.doi.org/10.3989/redc.2016.4.1356 [22 de enero de 2017].

Aguado-López, Eduardo et al. (2016), "El modelo de publicación ALyC: XML-JATS: XML JATS Redalyc”. Disponible en: https://xmljatsredalyc.org/xml-jats-en-redalyc/ [19 de noviembre de 2016].

Banerjee, Indrajit et al. (2015), “Tesis a favor de la consolidación del Acceso Abierto como una alternativa de democratización de la ciencia en América Latina”, en Suber, Peter, Acceso Abierto, México: UAEM. Disponible en: http://ri.uaemex.mx/bitstream/ handle/20.500.11799/21710/Acceso\%20Abierto.pdf ?sequence $=5$ [21 de noviembre de 2016].

Beigel, Fernanda (2015), “Los modos de la dependencia académica”, en Página 12. Disponible en: https://www.pagina12.com.ar/diario/universidad/10-280109-2015-08-25.html [22 de septiembre de 2016].

Beigel, Fernanda (2013), "Centros y periferias en la circulación internacional del conocimiento", en Nueva Sociedad, núm. 245, Argentina: Foro Nueva Sociedad. Disponible en: http://nuso.org/articulo/centros-y-periferias-en-la-circulacioninternacional-del-conocimiento/ [5 de diciembre de 2016].

Calvert, Ian (2017), "A new cartography of collaboration", en The connected culture of collaboration, Digital Science-Overleaf. Disponible en: https://www.digital-science. com/resources/portfolio-reports/connected-culture-collaboration/ [6 de marzo de 2017].

Comisión Europea y Science-Metrix (2015), "Analysis of bibliometric indicator for European policies, 2000-2013”, Bélgica: Comisión Europea. Disponible en: https://ec.europa. eu/research/innovation-union/pdf/bibliometric_indicators_for_european_policies. pdf [22 de enero de 2016].

Didou, Sylvie (2006), "Internacionalización de la educación superior y provisión transnacional de servicios educativos en América Latina: del voluntarismo a las elecciones estratégicas", en Seminario internacional IESALC-UNESCO/Conferencia de Rectores, Panamá: IESALC-UNESCO. Disponible en: http://firgoa.usc.es/drupal/ files/didou.pdf [1 de diciembre de 2016].

Fanelli, Daniele y Larivière, Vincent (2016), "Researcher' individual publication rate has not increased in a century”, en PLos ONE, vol. 11, núm. 3. Disponible en: http://journals. plos.org/plosone/article?id=10.1371/journal.pone.0149504 [15 de noviembre de 2016].

Frenken, Koen et al. (2010), “La globalización de la colaboración en investigación”, en UNESCO-Foro Consultivo Científico y Tecnológico, AC, Informe sobre las ciencias sociales en el mundo 2010. Las brechas del conocimiento, Francia: Unesco. Disponible en: http://unesdoc.unesco.org/images/0021/002173/217366s.pdf [3 de diciembre de 2016].

Gibbs, Wayt (1995), "Lost science in the third world", en Scientific American, vol. 273, núm. 2, Estados Unidos: Nature Publishing Group. Disponible en: https://www. researchgate.net/publication/259056309_Lost_Science_in_the_Third_World [18 de diciembre de 2016]. 
Gómez-Morales, Yuri (2015), "Usos y abusos de la bibliometría”, en Revista Colombiana de Antropología, vol. 51, núm. 1, Colombia: ICANH. Disponible en: http://www. redalyc.org/articulo.oa?id=105042615013 [16 de enero de 2017].

González Alcaide, Gregorio y Gómez Ferri, Javier (2014), "La colaboración científica: principales líneas de investigación y retos del futuro", en Revista Española de Documentación Cientifica, vol. 37, núm. 4, España: CSIC.. Disponible en http:// dx.doi.org/10.3989/redc.2014.4.1186 [19 de julio de 2016].

Hernández, José-Luis (2016), "La gestión editorial de revistas científicas hoy. La internacionalización de la comunidad científica”, en Aula Magna 2.0 blog. Disponible en: http://cuedespyd.hypotheses.org/1072 [2 de abril de 2017].

Hernández, Raúl (2014), "Nuevas y viejas potencias científicas” en ¿Quién escribe más y sobre qué? Cambios recientes en la geopolitica de la producción cientifica en América Latina y el Caribe, Perú: Instituto de Estudios Peruanos. Disponible en http://repositorio. minedu.gob.pe/handle/123456789/2788 [19 de febrero de 2017].

Kreimer, Pablo (2013), "Internacionalización y tensiones para un uso social de la ciencia latinoamericana. Del siglo XIX al XXI”, en Restrepo Forero, Olga [ed.], Proyecto ensamblado en Colombia. Ensamblando estados, Colombia: Universidad Nacional de Colombia. Disponible en: https://www.researchgate.net/publication/277250039_ Internacionalizacion_y_tensiones_para_un_uso_social_de_la_ciencia_ latinoamericana_Del_siglo_XIX_al_XXI [14 de abril de 2017].

Leydesdorff, Loet et al. (2013), "International collaboration in science: the global map and the network", en Elprofesional de la información, vol. 22, núm. 1, EPI S.C.P. Disponible en: https://arxiv.org/pdf/1301.0801.pdf [7 de abril de 2017].

Marin, Anabel et al. (2015), "Evaluación del impacto de las iniciativas de Acceso Abierto en el ámbito académico y otros”, en Alperin, Juan Pablo y Fischman, Gustavo [eds.], Hecho en Latinoamérica. Acceso Abierto, revistas académicas e innovaciones regionales, Argentina: CLACSO. Disponible en: http://biblioteca.clacso.edu.ar/clacso/ se/20150722110704/HechoEnLatinoamerica.pdf[25 de noviembre de 2016].

Mêgnigbêto, Eustache (2013), "International collaboration in scientific publishing: the case of West Africa (2001-2010)”, en Scientometrics, vol. 96, núm. 3, Estados Unidos: Springer. Disponible en: http://link.springer.com/article/10.1007/s11192-0130963-2 [30 de enero de 2017].

Mosbah-Natanson, Sébastien y Gingras, Yves (2013), “The globalization of social sciences? Evidence from quantitative analysis of 30 years of production, collaboration and citations in the social sciences (1980-2009)", en Current Sociology, vol. 62, núm. 5, Asociación Internacional de Sociología. Disponible en: http://journals.sagepub.com/ doi/abs/10.1177/0011392113498866 [15 de noviembre de 2016].

Orellano Narváez, Sergio Mario (2015), "La producción de la investigación: horizontes en la actualidad”, en Ventana Cientifica, vol. 6, núm. 10, Bolivia: Universidad Autónoma Juan Misael Saracho. Disponible en: http://www.revistasbolivianas.org.bo/pdf/rvc/ v6n10/v6n10_a07.pdf [24 de noviembre de 2016].

Paz, María (2015), “Cooperar... ¿ con quiénes y para qué?”, en Lago, Silvia y Horacio, Néstor [coords.], Desafíos y dilemas de la universidad y la ciencia en América Latina y el Caribe en el siglo XXI, Argentina: Siglo XXI. Disponible en: https://www.teseopress.com/ universidadyciencia/chapter/cooperar-con-quienes-y-para-que-apuntes-para-pensarla-cooperacion-internacional-en-el-marco-de-la-politica-cientifico-tecnologica-en-laargentina-actual-2/ [11 de noviembre de 2016]. 
Ruiz, Alejandro y Russell, Jane (2016), "La estructura del sistema científico de México a finales del siglo XX: una visión a nivel de instituciones", en Revista REDES, vol. 27, núm. 2, España: UAB y LRPC. Disponible en: http://dx.doi.org/10.5565/rev/ redes.626 [22 de noviembre de 2016].

Russell, Jane et al. (2007), "Colaboración científica entre países de la región latinoamericana”, en Revista Española de Documentación Cientifica, vol. 30, núm. 4, España: Consejo Superior de Investigaciones Científicas. Disponible en: http://redc.revistas.csic.es/ index.php/redc/article/viewFile/378/390 [15 de noviembre 2016].

Santos, José (2013), “Compra-venta de escrituras. El lugar de los académicos en el mercado de las textualidades”, en Revista Paralelaje, núm. 10. Disponible en: http://www. paralaje.cl/wp-content/uploads/2014/10/1-SANTOS-10-286-984-1-PB.pdf [18 de noviembre de 2017].

Science-metrix (2010), “30 Years in science. Secular movements in knowledge creation”, en Science-Metrix Canadá, Science Metrix EE.UU. Disponible en: http://www.sciencemetrix.com/sites/default/files/science-metrix/publications/30years-paper.pdf [3 de marzo de 2017].

Varun, S. y Bhattacharya, Sujit (2014), "Forecasting the trend of international scientific collaboration”, en Scientometrics, vol. 101, núm. 3, Springer. Disponible en: http:// link.springer.com/article/10.1007/s11192-014-1364-x [3de febrero de 2017].

Vessuri, Hebe (2009), "Cambios recientes en la internacionalización de las ciencias sociales: la socialidad de redes impacta América Latina”, en Didou, Sylvie y Gérard, Etienne [eds.], Fuga de cerebros, movilidad académica, redes cientificas. Perspectivas latinoamericanas, México: CINVESTAV. Disponible en: http://www.iesalc.unesco. org.ve $/$ index.php?option $=$ com_fabrik\&view=details\&formid $=2 \&$ rowid=40\&lang $=$ es [25 de enero de 2016].

\section{Anexo}

\section{Figura 1}

\section{Universo de estudio}

\begin{tabular}{lcc}
\hline & CS & AyH \\
\hline Interacciones & 9,902 & 430 \\
\hline Disciplinas & 20 & 5 \\
\hline Países & 98 & 35 \\
\hline Instituciones & 11,826 & 488 \\
\hline Revistas & 645 & 92 \\
\hline
\end{tabular}

Fuente: redalyc.org, UAEM. 
Figura 2

\section{Inclusión de los países de Latinoamérica y el Caribe en el diálogo científico internacional de CS y AyH, 2005-2015}

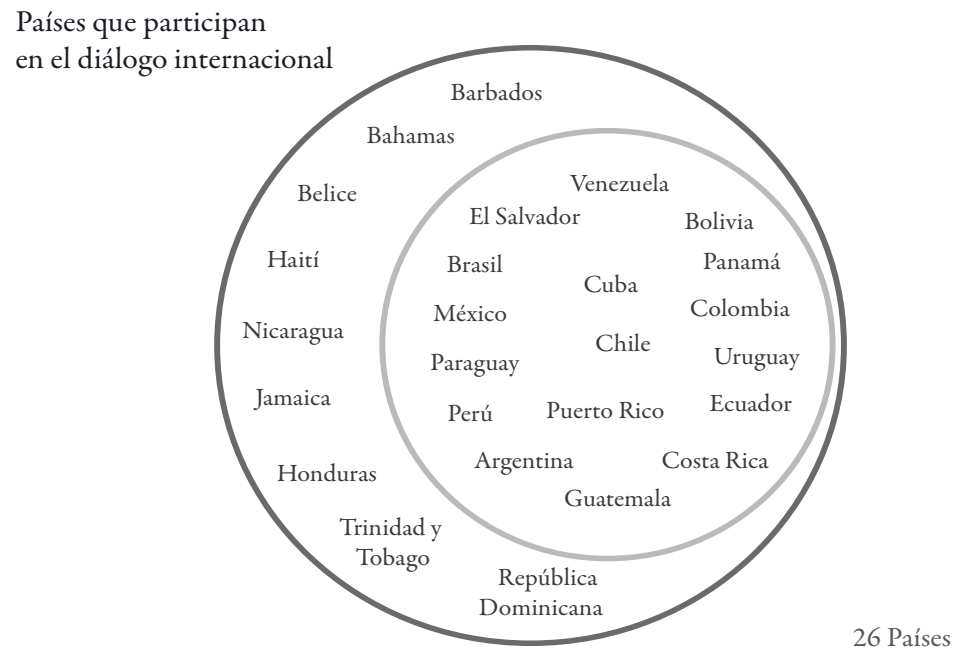

Países que permanecen aislados del diálogo internacional

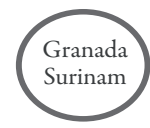

\section{Haití}

Barbados

R. Dominicana

Trinidad y Tobago

Nicaragua

Guyana

Jamaica

Países que no cuentan con producción científica

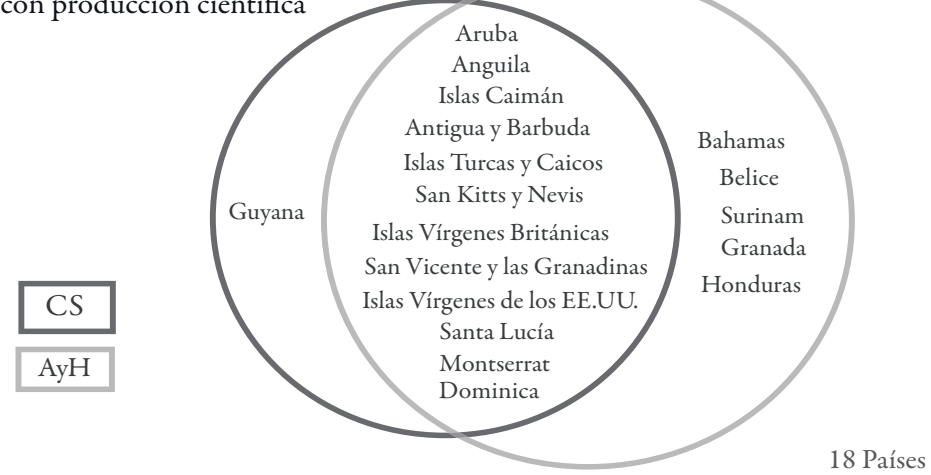

Fuente: redalyc.org, UAEM. 
Figura 3

\section{Producción y Tasa de Crecimiento Media Acumulada de las interacciones internacionales por país. CS, 2005-2015}

\begin{tabular}{|c|c|c|c|}
\hline & & Producción & \%TCMA \\
\hline 1 & Colombia & 16,294 & 17.5 \\
\hline 2 & Brasil & 49,741 & 17.0 \\
\hline 3 & México & 22,566 & 11.0 \\
\hline 4 & Argentina & 11,113 & 25.7 \\
\hline 5 & Chile & 7,866 & 16.8 \\
\hline 6 & Venezuela & 6,653 & 10.6 \\
\hline 7 & Ecuador & 623 & 60.7 \\
\hline 8 & Bolivia & 550 & 43.8 \\
\hline 9 & Costa Rica & 2,055 & 27.9 \\
\hline 10 & Perú & 1,814 & 23.1 \\
\hline 11 & Cuba & 2,423 & 21.6 \\
\hline 12 & Uruguay & 722 & 20.7 \\
\hline 13 & Nicaragua & 62 & 141.4 \\
\hline 14 & Panamá & 53 & 119.5 \\
\hline 15 & R. Dominicana & 206 & 108.7 \\
\hline 16 & Guatemala & 101 & 95.0 \\
\hline 17 & Paraguay & 70 & 61.4 \\
\hline 18 & Puerto Rico & 356 & 59.8 \\
\hline 19 & Honduras & 27 & 50.8 \\
\hline 20 & El Salvador & 59 & 46.0 \\
\hline 21 & Jamaica & 12 & 10.0 \\
\hline 22 & Haití & 5 & 10.0 \\
\hline 23 & Belice & 4 & -9.2 \\
\hline 24 & Bahamas & 3 & 0.0 \\
\hline 25 & Barbados & 3 & 0.0 \\
\hline 26 & Trinidad y Tobago & 3 & 0.0 \\
\hline & $\begin{array}{l}\text { Actividad consolidada } \\
\text { Actividad alta }\end{array}$ & $\begin{array}{l}\text { Acti } \\
\text { Acti }\end{array}$ & \\
\hline
\end{tabular}

Fuente: redalyc.org, UAEM. 


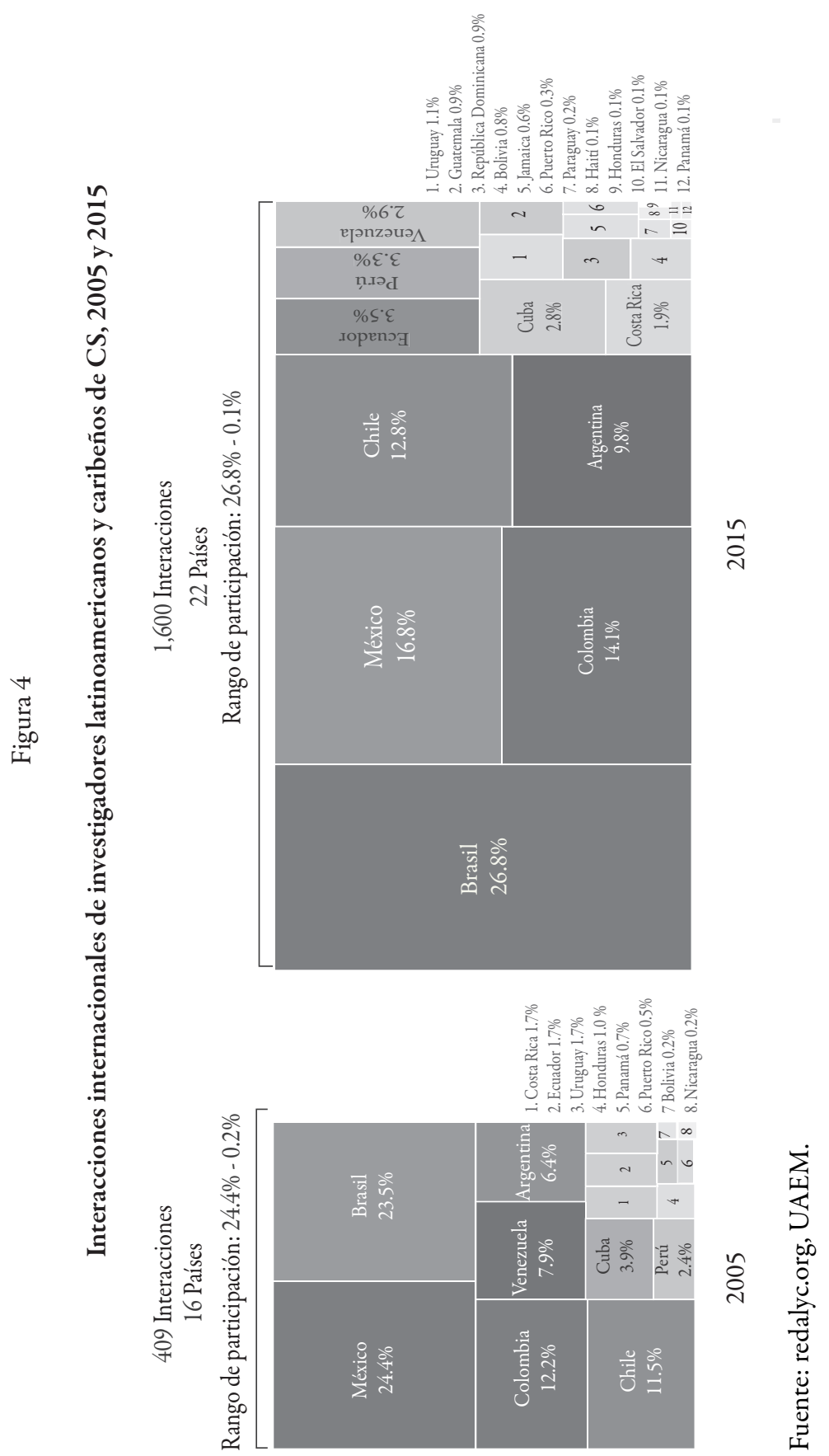


Eduardo Aguado-López, Arianna Becerril-García y Sheila Godínez-Larios. Colaboración internacional en las ciencias sociales y humanidades: inclusión, participación e integración

Figura 5

Interacciones internacionales y proporción de la colaboración por países.

CS, 2005 y 2015

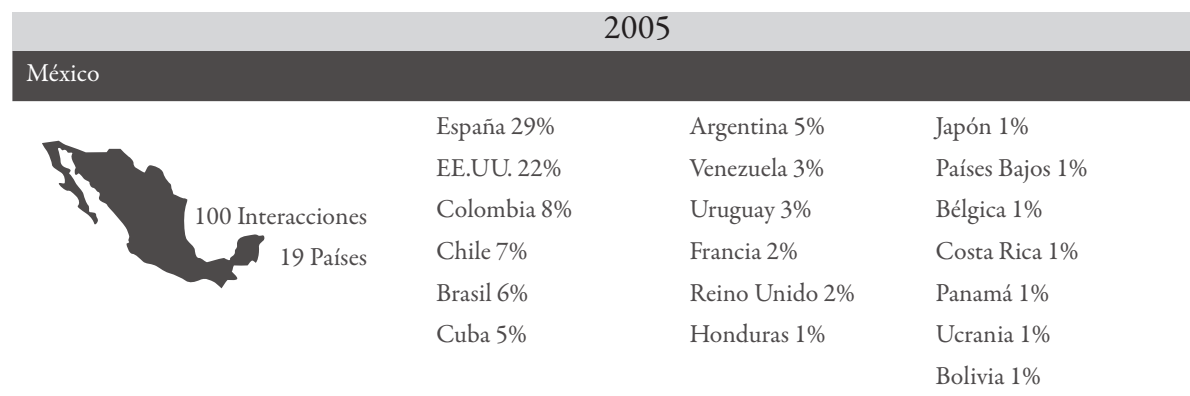

$\begin{array}{llll}\text { Brasil } & \text { EE. UU. 17.7\% } & \text { Canadá 4.2\% } & \text { Perú 1\% } \\ & \text { España 16.7\% } & \text { Chile 3.1\% } & \text { Noruega 1\% } \\ & \text { Reino Unido 11.5\% } & \text { Países Bajos 2.1\% } & \text { Japón 1\% } \\ \text { 22 Países } & \text { Portugal 9.4\% } & \text { Suiza 2.1\% } & \text { Finlandia 1\% } \\ & \text { Argentina 8.3\% } & \text { Cuba 2.1\% } & \text { Uruguay 1\% } \\ & \text { México 6.3\% } & \text { Timor Oriental 1\% } & \text { Colombia 1\% } \\ & \text { Francia 6.3\% } & \text { Emiratos Árabes 1\% } & \text { Cabo Verde 1\% } \\ & \text { Venezuela 1\% } & & \end{array}$

Colombia

$\begin{array}{rlll} & \text { EE. UU. 26\% } & \text { Reino Unido 4\% } & \text { Argentina 2\% } \\ & \text { España 18\% } & \text { Australia 4\% } & \text { Brasil 2\% } \\ \text { 15 Países } & \text { México 16\% } & \text { Costa Rica 2\% } & \text { Honduras 2\% } \\ \text { Chile 10\% Interacciones } & \text { Venezuela 6\% } & \text { Francia 2\% } & \text { Canadá 2\% } \\ & & \text { Vaticano 2\% } & \text { Puerto Rico 2\% }\end{array}$

\section{Chile}

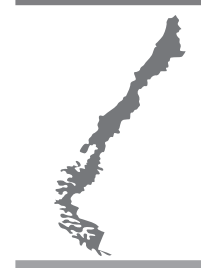

España $25.1 \%$
EE. UU. $14.9 \%$
México $14.9 \%$
Colombia $10.6 \%$
Brasil $6.4 \%$

Argentina 6.4\%

Francia 2.1\%

15 Países

47 Interacciones

Brasil 6.4\%

Reino Unido 4.3\%

Ecuador 2.1\%

Venezuela $2.1 \%$

Canadá 2.1\%

Austria 2.1\%

Australia 2.1\%

Uruguay $2.1 \%$

Cuba 2.1\%

\section{Venezuela}

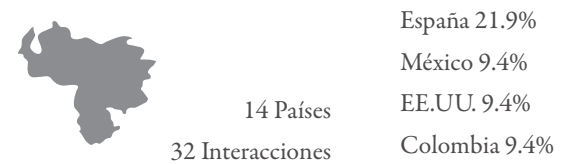

$\begin{array}{ll}\text { Bélgica 9.4\% } & \text { Japón 3.1\% } \\ \text { Francia 9.4\% } & \text { Irán 3.1\% } \\ \text { Perú 6.3\% } & \text { Brasil 3.1\% } \\ \text { Nueva Zelanda 6.3\% } & \text { Ecuador 3.1\% } \\ \text { Chile 3.1\% } & \text { Costa Rica 3.1\% }\end{array}$


Convergencia Revista de Ciencias Sociales, núm. 75, 2017, Universidad Autónoma del Estado de México

\begin{tabular}{|c|c|c|c|c|}
\hline \multicolumn{5}{|l|}{ Argentina } \\
\hline & & Brasil 30.8\% & Chile 11.5\% & EE.UU. 3.8\% \\
\hline & 8 Países & México 19.2\% & Francia $7.7 \%$ & Suiza $3.8 \%$ \\
\hline & 26 Interacciones & España 19.2\% & Colombia 3.8\% & \\
\hline \multicolumn{5}{|l|}{ Costa Rica } \\
\hline & 6 Países & EE.UU. 28.6\% & Colombia 14.3\% & Suiza $14.3 \%$ \\
\hline & 16 Interacciones & México 14.3\% & Venezuela $14.3 \%$ & España 14.3\% \\
\hline \multicolumn{5}{|l|}{ Cuba } \\
\hline & 6 Países & España 37.5\% & Brasil 12.5\% & Ecuador $6.3 \%$ \\
\hline & 16 Interacciones & México 31.3\% & EE.UU. 6.3\% & Chile .3\% \\
\hline \multicolumn{5}{|l|}{ Perú } \\
\hline & 6 Países & España 30\% & Venezuela 20\% & Bélgica 10\% \\
\hline & 10 Interacciones & EE. UU. $20 \%$ & Panamá 10\% & Brasil 10\% \\
\hline \multicolumn{5}{|l|}{ Ecuador } \\
\hline & 6 Países & España 28.6\% & Cuba 14.3\% & Bélgica 14.3\% \\
\hline & 7 Interacciones & Chile 14.3\% & Canadá $14.3 \%$ & Venezuela $14.3 \%$ \\
\hline \multicolumn{5}{|l|}{ Uruguay } \\
\hline & 5 Países & México 42.9\% & España 14.3\% & EE.UU. 14.3\% \\
\hline & 7 Interacciones & Chile 14.3\% & Brasil 14.3\% & \\
\hline \multicolumn{5}{|l|}{ Honduras } \\
\hline & 4 Países & España 25\% & México 25\% & \\
\hline & 4 Interacciones & Australia 25\% & Colombia 25\% & \\
\hline \multicolumn{5}{|l|}{ Panamá } \\
\hline & 3 Países & Perú 33.3\% & EE. UU. $33.3 \%$ & \\
\hline & 3 Interacciones & México 33.3\% & & \\
\hline \multicolumn{5}{|c|}{ Puerto Rico } \\
\hline & 2 Países & Colombia 50\% & & \\
\hline & 2 Interacciones & EE. UU. 50\% & & \\
\hline \multicolumn{5}{|l|}{ Bolivia } \\
\hline & 1 País & México 100\% & & \\
\hline & 1Interacción & & & \\
\hline \multicolumn{5}{|l|}{ Nicaragua } \\
\hline & 1 País & Bélgica 100\% & & \\
\hline & 1 Interacción & & & \\
\hline
\end{tabular}


Eduardo Aguado-López, Arianna Becerril-García y Sheila Godínez-Larios. Colaboración internacional en las ciencias sociales y humanidades: inclusión, participación e integración

\section{5}

Brasil

\begin{tabular}{|c|c|c|c|}
\hline & Portugal $26.2 \%$ & Bélgica $0.7 \%$ & Lituania $0.2 \%$ \\
\hline & España $15.2 \%$ & Nueva Zelanda $0.7 \%$ & R. Serbia $0.2 \%$ \\
\hline & EE.UU. 9.6\% & Dinamarca $0.7 \%$ & Corea $0.2 \%$ \\
\hline & Colombia $6.3 \%$ & Países Bajos 0.7\% & Albania $0.2 \%$ \\
\hline & Francia $4.9 \%$ & Polonia $0.5 \%$ & Nigeria $0.2 \%$ \\
\hline & Canadá 4.7\% & Cuba $0.5 \%$ & Noruega $0.2 \%$ \\
\hline & Argentina 5.8\% & Japón $0.5 \%$ & Mozambique $0.2 \%$ \\
\hline & Reino Unido $3.5 \%$ & Ecuador $0.5 \%$ & Austria $0.2 \%$ \\
\hline & Chile $2.8 \%$ & Angola $0.5 \%$ & Irlanda $0.2 \%$ \\
\hline & México 1.9\% & Suiza $0.5 \%$ & Rumania $0.2 \%$ \\
\hline 48 Países & Australia 1.6\% & Bolivia $0.5 \%$ & Grecia $0.2 \%$ \\
\hline 428 Interacciones & Alemania 1.6\% & Organismo & Egipto $0.2 \%$ \\
\hline & Uruguay $1.2 \%$ & Internacional $0.5 \%$ & Rusia $0.2 \%$ \\
\hline & Costa Rica $0.9 \%$ & Sudáfrica $0.2 \%$ & Islandia $0.2 \%$ \\
\hline & Italia $0.9 \%$ & Paraguay $0.2 \%$ & China $0.2 \%$ \\
\hline & Venezuela $0.9 \%$ & Eslovenia $0.2 \%$ & \\
\hline & Perú $0.9 \%$ & Corea del Sur $0.2 \%$ & \\
\hline
\end{tabular}

México

$\begin{array}{rlll} & \text { España 33.5\% } & \text { Costa Rica 1.5\% } & \text { Bélgica 0.4\% } \\ & \text { EE.UU. 17.1\% } & \text { Francia 1.1\% } & \text { Finlandia 0.4\% } \\ & \text { Colombia 13\% } & \text { Guatemala 1.1\% } & \text { Camerún 0.4\% } \\ & \text { Chile 5.2\% } & \text { Ecuador 1.1\% } & \text { Noruega 0.4\% } \\ & \text { Argentina 4.1\% } & \text { Cuba 1.1\% } & \text { Corea 0.4\% } \\ & \text { Brasil 3\% } & \text { Suiza 0.7\% } & \text { Herzegovina y Bosnia } \\ & \text { Canadá 2.6\% } & \text { Portugal 0.7\% } & \text { 0.4\% } \\ & \text { Reino Unido 2.6\% } & \text { Nueva Zelanda 0.4\% } & \text { Nicaragua 0.4\% } \\ & \text { Venezuela 2.2\% } & \text { Eslovaquia 0.4\% } & \text { China 0.4\% } \\ & \text { Alemania 2.2\% } & \text { Suecia 0.4\% } & \text { Uruguay 0.4\% } \\ & \text { Perú 1.9\% } & \text { Bolivia 0.4\% } & \text { Italia 0.4\% }\end{array}$

Colombia

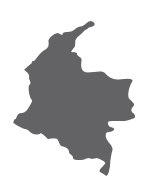

24 Países

225 Interacciones
España $31.1 \%$

México 15.6\%

Brasil $12 \%$

EE.UU. 7.6\%

Argentina 5.8\%

Chile 4\%

Francia 2.7\%

Reino Unido $2.7 \%$
Cuba 2.2\%

Alemania 2.2\%

Perú 1.8\%

Italia $1.8 \%$

Ecuador 1.3\%

Israel $0.9 \%$

Costa Rica 0.9\%

Noruega $0.6 \%$
Organismo

Internacional $0.4 \%$

Bolivia $0.4 \%$

Guatemala 0.4\%

Nueva Zelanda $0.4 \%$

Suecia $0.4 \%$

R. Dominicana $0.4 \%$

Venezuela $4 \%$

Bélgica $0.4 \%$ 


\begin{tabular}{|c|c|c|c|c|}
\hline \multicolumn{5}{|l|}{ Chile } \\
\hline & & España 39.2\% & Canadá $2 \%$ & Uruguay $0.5 \%$ \\
\hline & & Argentina $8.8 \%$ & Ecuador 2\% & Países Bajos 0.5\% \\
\hline & & EE.UU. 6.9\% & Alemania $2 \%$ & Costa Rica $0.5 \%$ \\
\hline & & México $6.9 \%$ & Portugal $1 \%$ & Panamá $0.5 \%$ \\
\hline & & Brasil 5.9\% & Bolivia 1\% & Venezuela $0.5 \%$ \\
\hline & & Francia $4.4 \%$ & Australia1\% & Finlandia $0.5 \%$ \\
\hline & & Perú $4.4 \%$ & Bélgica 1\% & Italia $0.5 \%$ \\
\hline & 28 Países & Colombia $4.4 \%$ & Dinamarca $1 \%$ & Suiza $0.5 \%$ \\
\hline & 204 Interacciones & Reino Unido $3.4 \%$ & Organismo & Eslovenia $0.5 \%$ \\
\hline & & & Internacional $0.5 \%$ & Rumania 0.5\% \\
\hline \multicolumn{5}{|l|}{ Argentina } \\
\hline & & España 16.7\% & Italia $1.3 \%$ & Corea $0.6 \%$ \\
\hline & & Brasil 16\% & Canadá $1.3 \%$ & Lituania $0.6 \%$ \\
\hline & & Chile $11.5 \%$ & Venezuela $1.3 \%$ & Alemania $0.6 \%$ \\
\hline & & Colombia 8.3\% & Bolivia 1.3\% & Paraguay $0.6 \%$ \\
\hline & & México $7.1 \%$ & Guatemala $1.3 \%$ & Rusia $0.6 \%$ \\
\hline & & EE.UU. 6.4\% & R. de Serbia 0.6\% & Polonia $0.6 \%$ \\
\hline & & Francia $4.5 \%$ & Bélgica $0.6 \%$ & Corea del Sur $0.6 \%$ \\
\hline$\gamma$ & 36 Países & Perú 3.2\% & Albania $0.6 \%$ & Islandia $0.6 \%$ \\
\hline & 156 Interacciones & Uruguay $2.6 \%$ & China $0.6 \%$ & Portugal $0.6 \%$ \\
\hline & & Cuba 1.9\% & Noruega $0.6 \%$ & Japón $0.6 \%$ \\
\hline & & Reino Unido $1.3 \%$ & Pakistán 0.6\% & R. Dominicana $0.6 \%$ \\
\hline & & Costa Rica 1.3\% & & \\
\hline
\end{tabular}

\begin{tabular}{|c|c|c|c|c|}
\hline \multicolumn{5}{|l|}{ Ecuador } \\
\hline & & España $33.9 \%$ & Colombia $5.4 \%$ & Países Bajos 1.8\% \\
\hline & & Cuba $23.2 \%$ & Brasil 3.6\% & El Salvador $1.8 \%$ \\
\hline & & Chile $7.1 \%$ & Costa Rica $1.8 \%$ & Argentina $1.8 \%$ \\
\hline & 16 Países & Canadá 5.4\% & Puerto Rico $1.8 \%$ & Perú $1.8 \%$ \\
\hline & 56 Interacciones & México $5.4 \%$ & EE.UU. 1.8\% & Venezuela $1.8 \%$ \\
\hline & & & & Etiopía $1.2 \%$ \\
\hline \multicolumn{5}{|l|}{ Perú } \\
\hline & & Chile $17 \%$ & Colombia $7.5 \%$ & Alemania $1.9 \%$ \\
\hline & & EE.UU. $13.2 \%$ & Cuba $3.8 \%$ & Francia $1.9 \%$ \\
\hline & & España $11.3 \%$ & Costa Rica 3.8\% & Organismo \\
\hline & & Argentina $9.4 \%$ & Países Bajos 1.9\% & Internacional $1.9 \%$ \\
\hline & 18 Países & México $9.4 \%$ & Ecuador $1.9 \%$ & Guatemala $1.9 \%$ \\
\hline & 53 Interacciones & Brasil 7.5\% & Venezuela $1.9 \%$ & Canadá 1.9\% \\
\hline & & & & Uruguay $1.9 \%$ \\
\hline
\end{tabular}


Eduardo Aguado-López, Arianna Becerril-García y Sheila Godínez-Larios. Colaboración internacional en las ciencias sociales y humanidades: inclusión, participación e integración

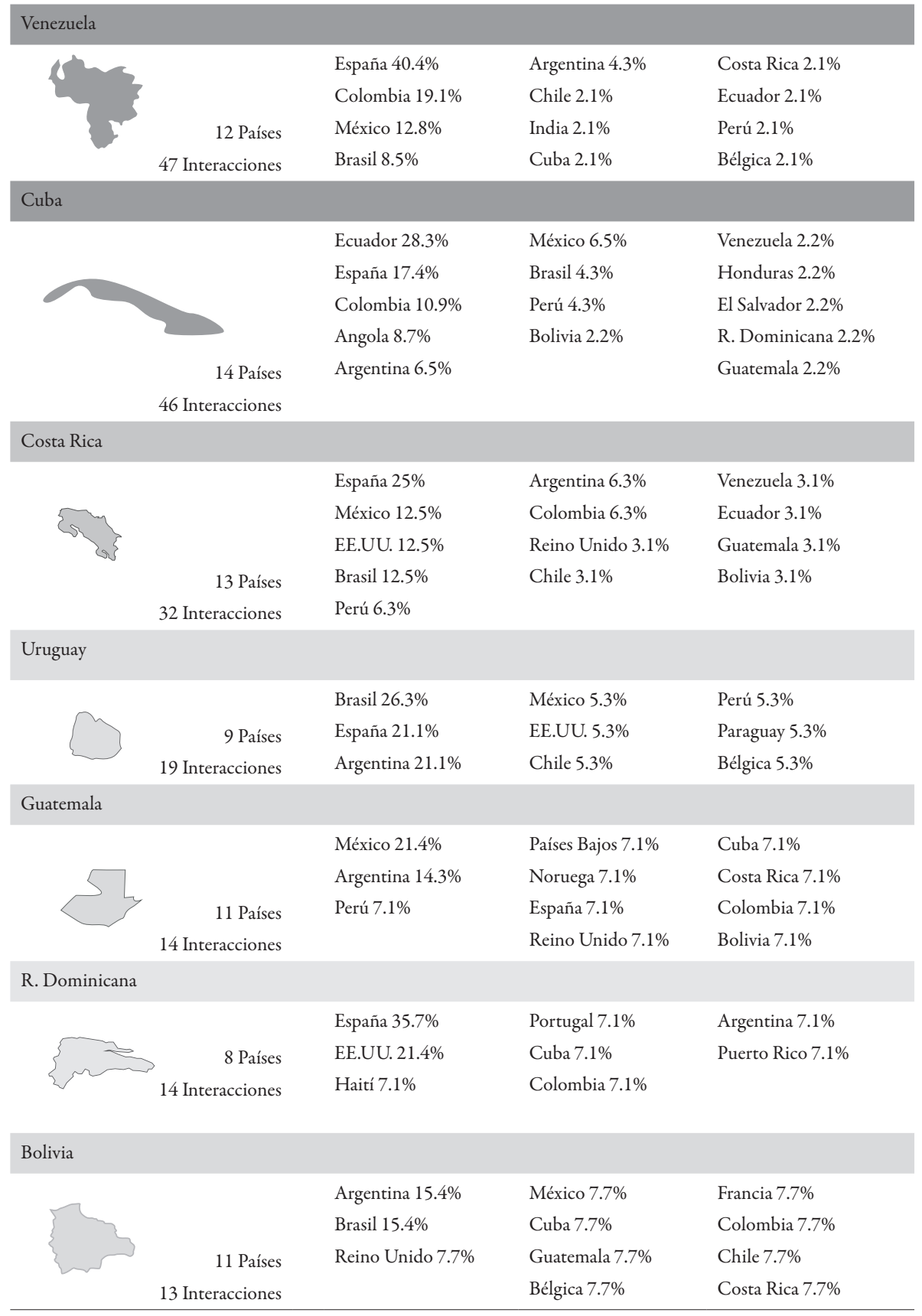


Convergencia Revista de Ciencias Sociales, núm. 75, 2017, Universidad Autónoma del Estado de México

\begin{tabular}{|c|c|c|c|c|}
\hline \multicolumn{5}{|l|}{ Jamaica } \\
\hline & & Reino Unido $11.1 \%$ & Túnez 11.1\% & Suiza $11.1 \%$ \\
\hline & 9 Países & Noruega $11.1 \%$ & India11.1\% & EE.UU. $11.1 \%$ \\
\hline & 9 Interacciones & Ruanda $11.1 \%$ & China $11.1 \%$ & Botsuana $11.1 \%$ \\
\hline \multicolumn{5}{|l|}{ Puerto Rico } \\
\hline & 4 Países & R. Dominicana $20 \%$ & Ecuador $20 \%$ & \\
\hline & 5 Interacciones & España 20\% & EE.UU. $40 \%$ & \\
\hline \multicolumn{5}{|l|}{ Paraguay } \\
\hline & 3 Países & Brasil 33.3\% & Uruguay $33.3 \%$ & \\
\hline & 3 Interacciones & Argentina 33.\% & & \\
\hline \multicolumn{5}{|l|}{ El Salvador } \\
\hline & 2 Países & Ecuador $50 \%$ & & \\
\hline & 2 Interacciones & Cuba $50 \%$ & & \\
\hline \multicolumn{5}{|l|}{ Panamá } \\
\hline & 2 Países & España 50\% & & \\
\hline & Interacciones & Chile $50 \%$ & & \\
\hline \multicolumn{5}{|l|}{ Haití } \\
\hline & 1 País & R. Dominicana 100\% & & \\
\hline & 1 Interacción & & & \\
\hline \multicolumn{5}{|l|}{ Honduras } \\
\hline & 1 País & Cuba $100 \%$ & & \\
\hline & 1 Interacción & & & \\
\hline \multicolumn{5}{|l|}{ Nicaragua } \\
\hline & 1 País & México 100\% & & \\
\hline & 1 Interacción & & & \\
\hline
\end{tabular}

\section{Interaccciones}

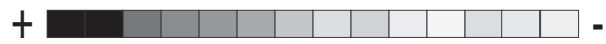

Fuente: redalyc.org, UAEM. 
Eduardo Aguado-López, Arianna Becerril-García y Sheila Godínez-Larios. Colaboración internacional en las ciencias sociales y humanidades: inclusión, participación e integración

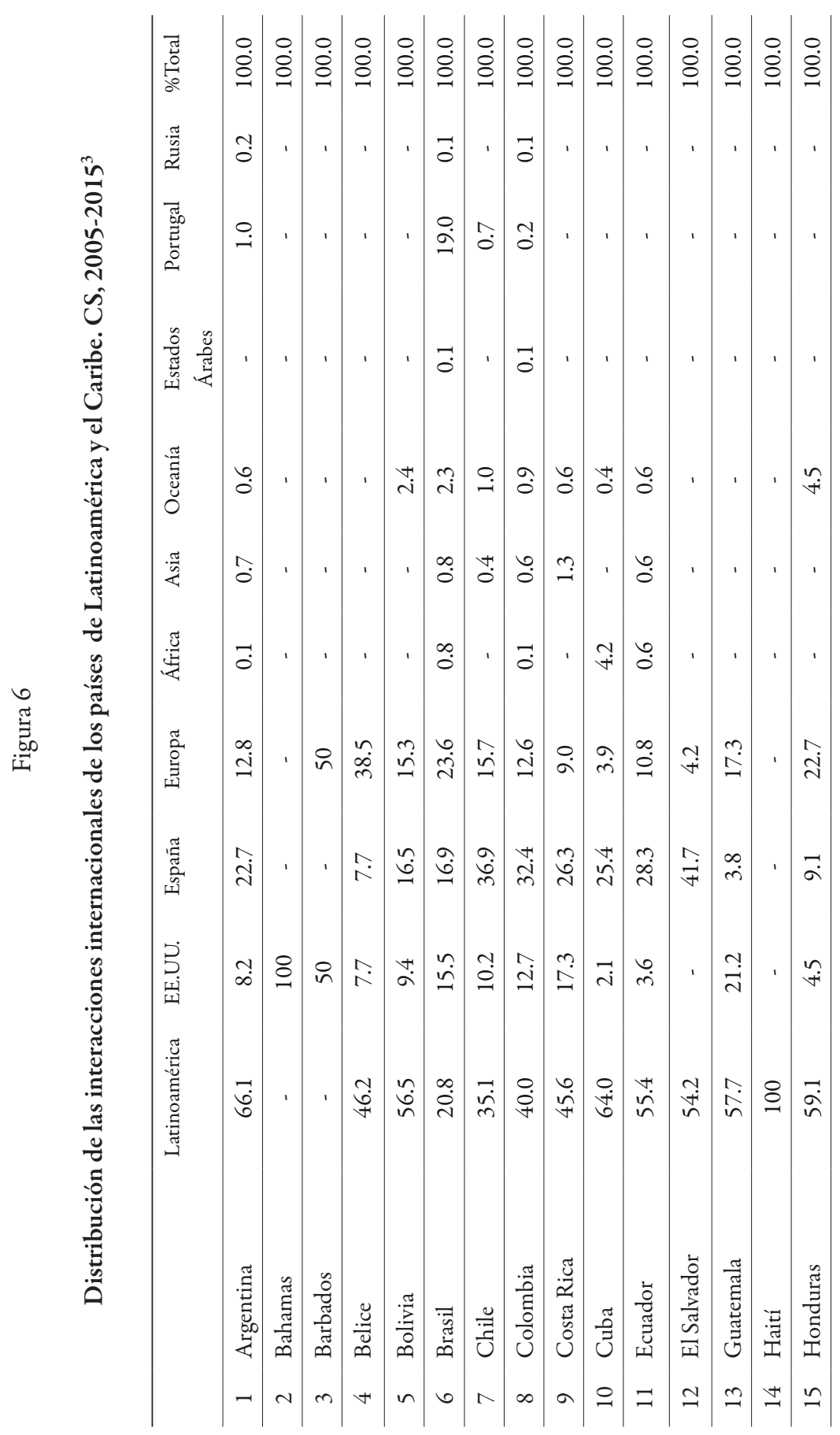




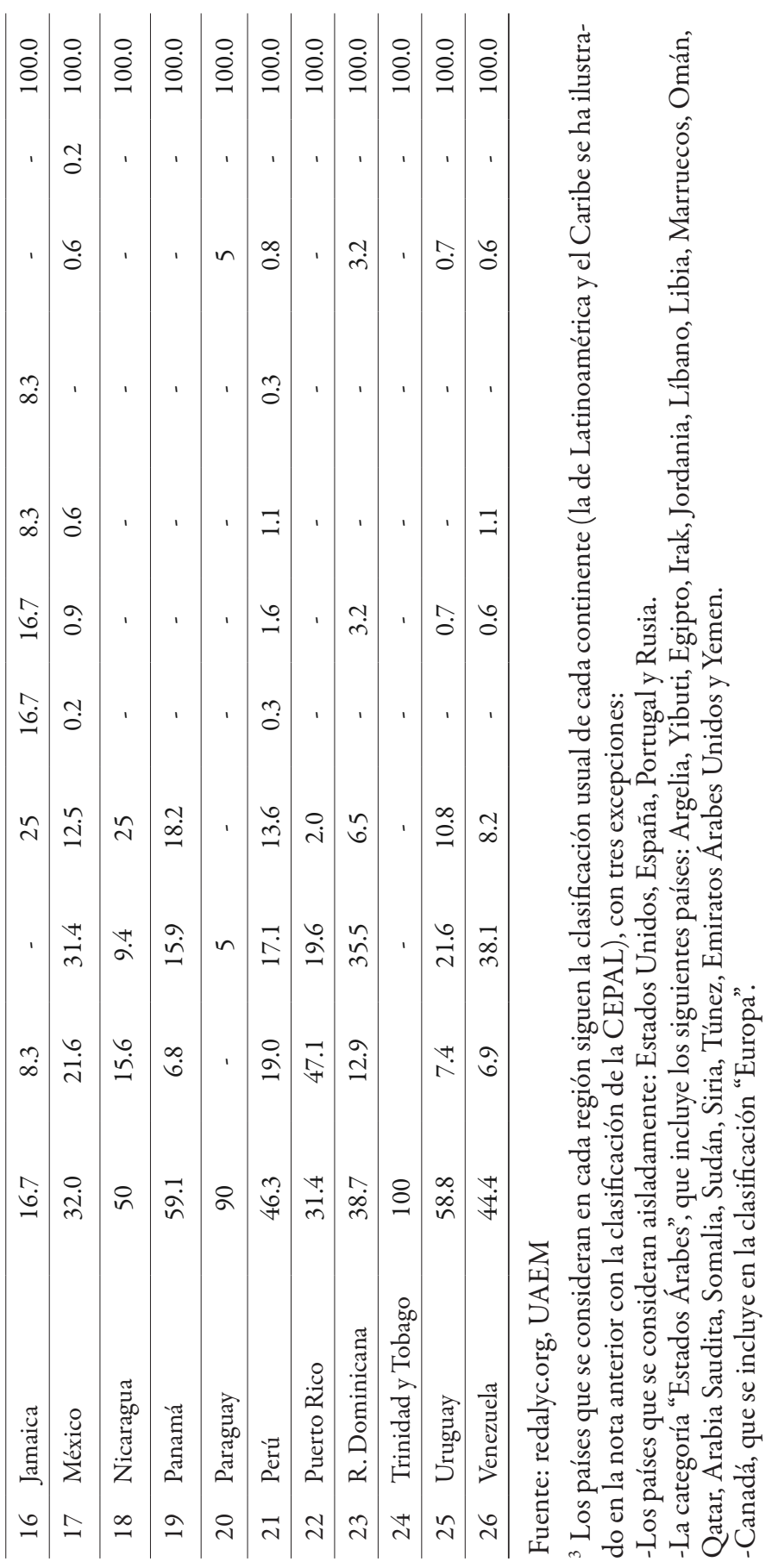


Eduardo Aguado-López, Arianna Becerril-García y Sheila Godínez-Larios. Colaboración internacional en las ciencias sociales y humanidades: inclusión, participación e integración

\section{Figura 7}

\section{Producción y Tasa de Crecimiento Media Acumulada de las interacciones internacionales por país. AyH, 2005-2015}

\begin{tabular}{clcc}
\hline & & Producción & \%TCMA \\
\hline 1 & México & 2,619 & 104.5 \\
\hline 2 & Argentina & 2,429 & 89.4 \\
\hline 3 & Chile & 2,880 & 74.0 \\
\hline 4 & Colombia & 3,081 & 59.7 \\
\hline 5 & Brasil & 4,673 & 32.7 \\
\hline 6 & Perú & 166 & 78.9 \\
\hline 7 & Venezuela & 490 & 16.7 \\
\hline 8 & Cuba & 301 & 16.7 \\
\hline 9 & Costa Rica & 253 & -10.0 \\
\hline 10 & Uruguay & 78 & 10.0 \\
\hline 11 & Ecuador & 51 & 10.0 \\
\hline 12 & Puerto Rico & 32 & 10.0 \\
\hline 13 & Panamá & 13 & 0.0 \\
\hline 14 & El Salvador & 9 & 0.0 \\
\hline 15 & Guatemala & 8 & 0.0 \\
\hline 16 & Paraguay & 7 & 0.0 \\
\hline \hline Actividad consolidada & & \\
\hline Actividad alta & Actividad media & & \\
\hline & & & \\
\hline
\end{tabular}

Fuente: redalyc.org, UAEM. 


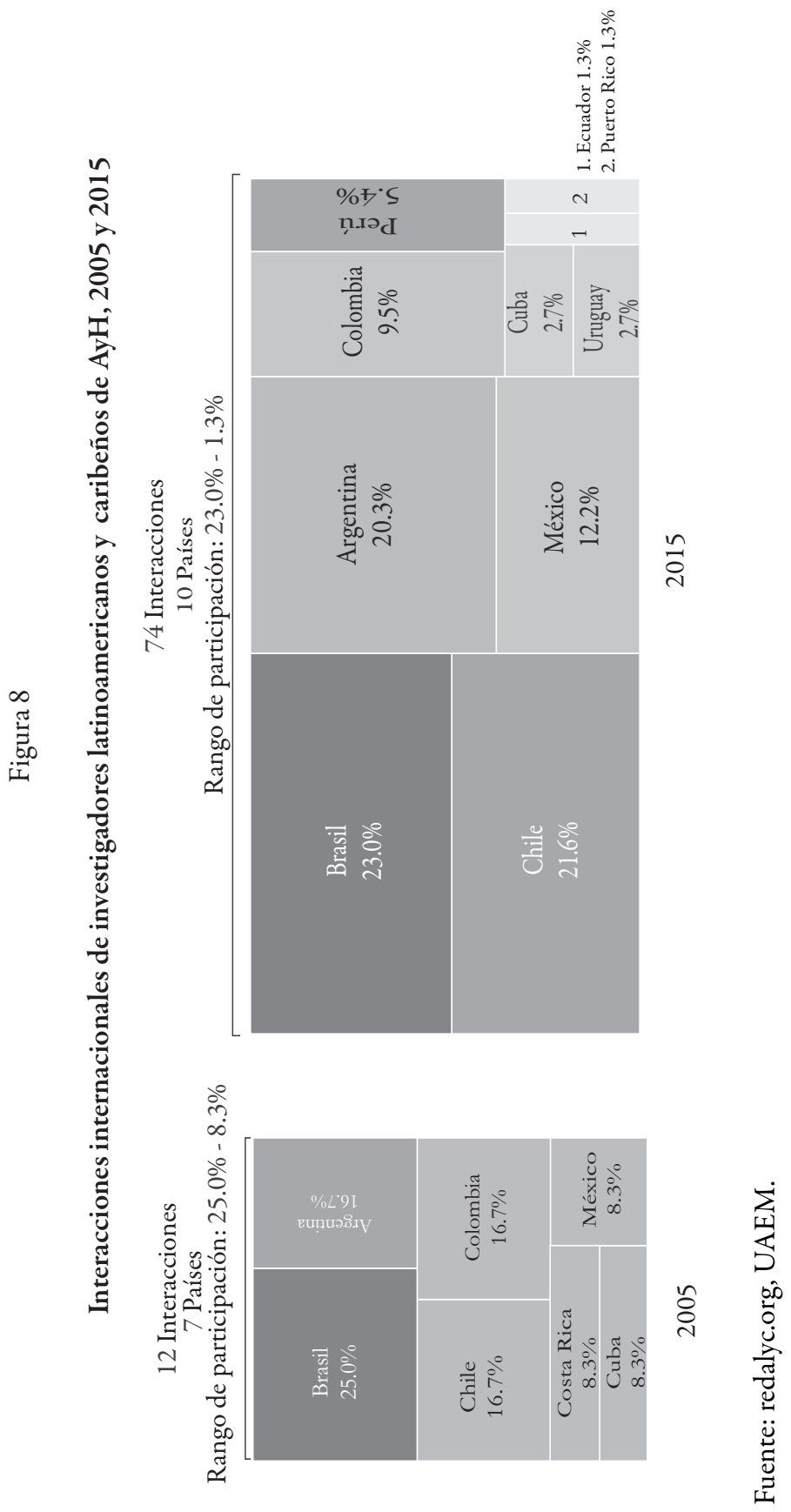


Eduardo Aguado-López, Arianna Becerril-García y Sheila Godínez-Larios. Colaboración internacional en las ciencias sociales y humanidades: inclusión, participación e integración

Figura 9

\section{Interacciones internacionales y proporción de la colaboración por países.}

AyH, 2005 y 2015

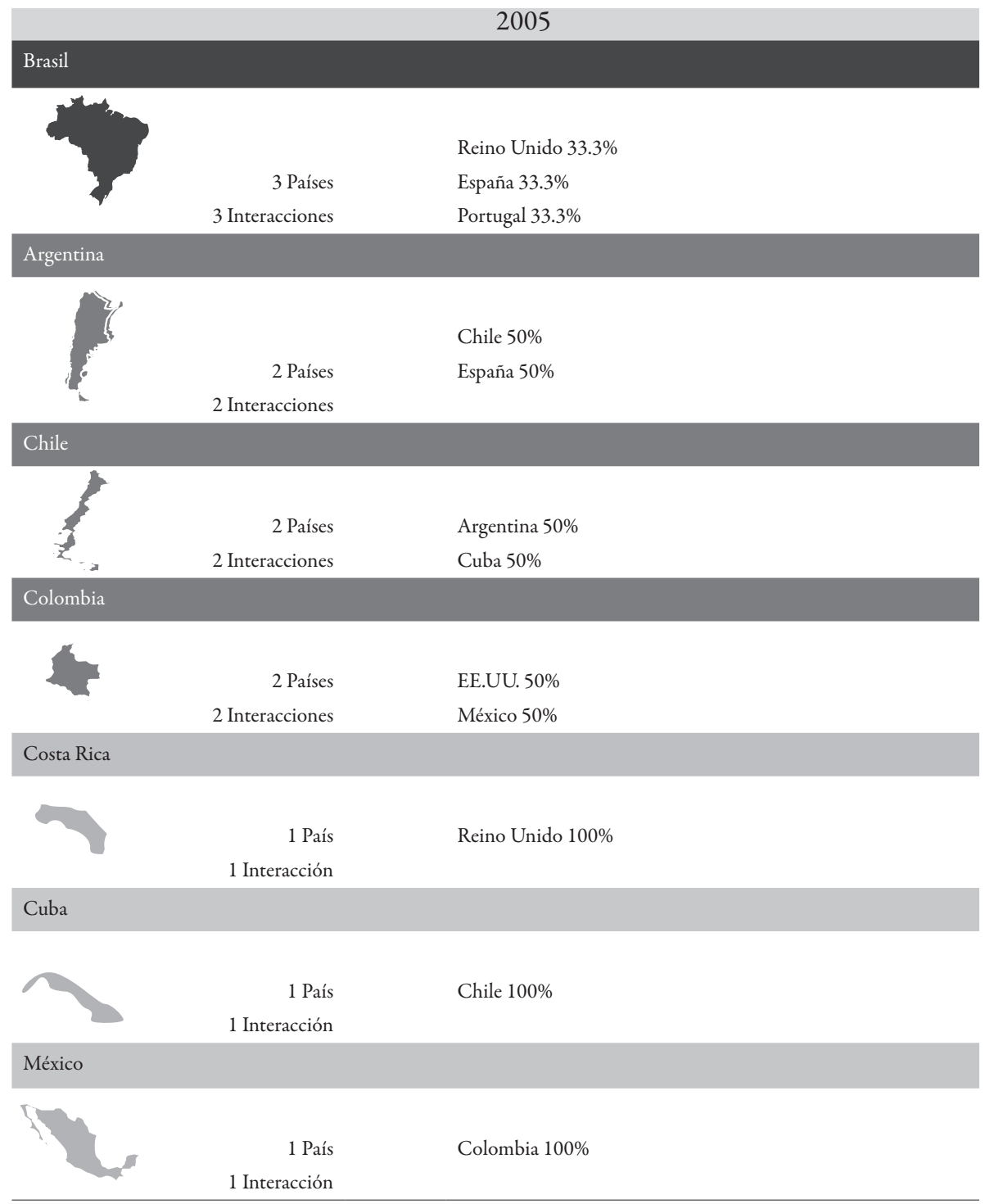


Convergencia Revista de Ciencias Sociales, núm. 75, 2017, Universidad Autónoma del Estado de México

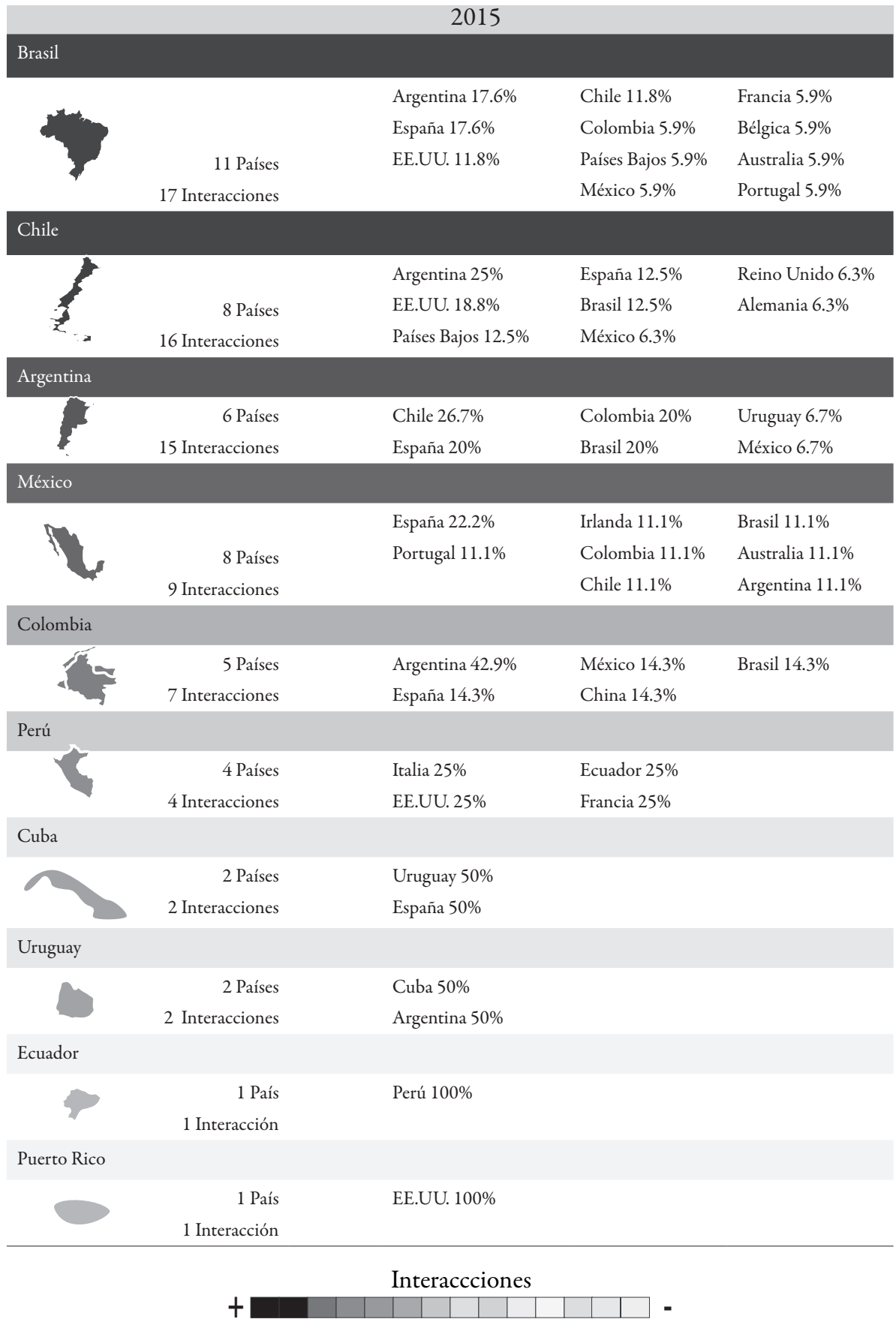

Fuente: redalyc.org, UAEM. 
Eduardo Aguado-López, Arianna Becerril-García y Sheila Godínez-Larios. Colaboración internacional en las ciencias sociales y humanidades: inclusión, participación e integración

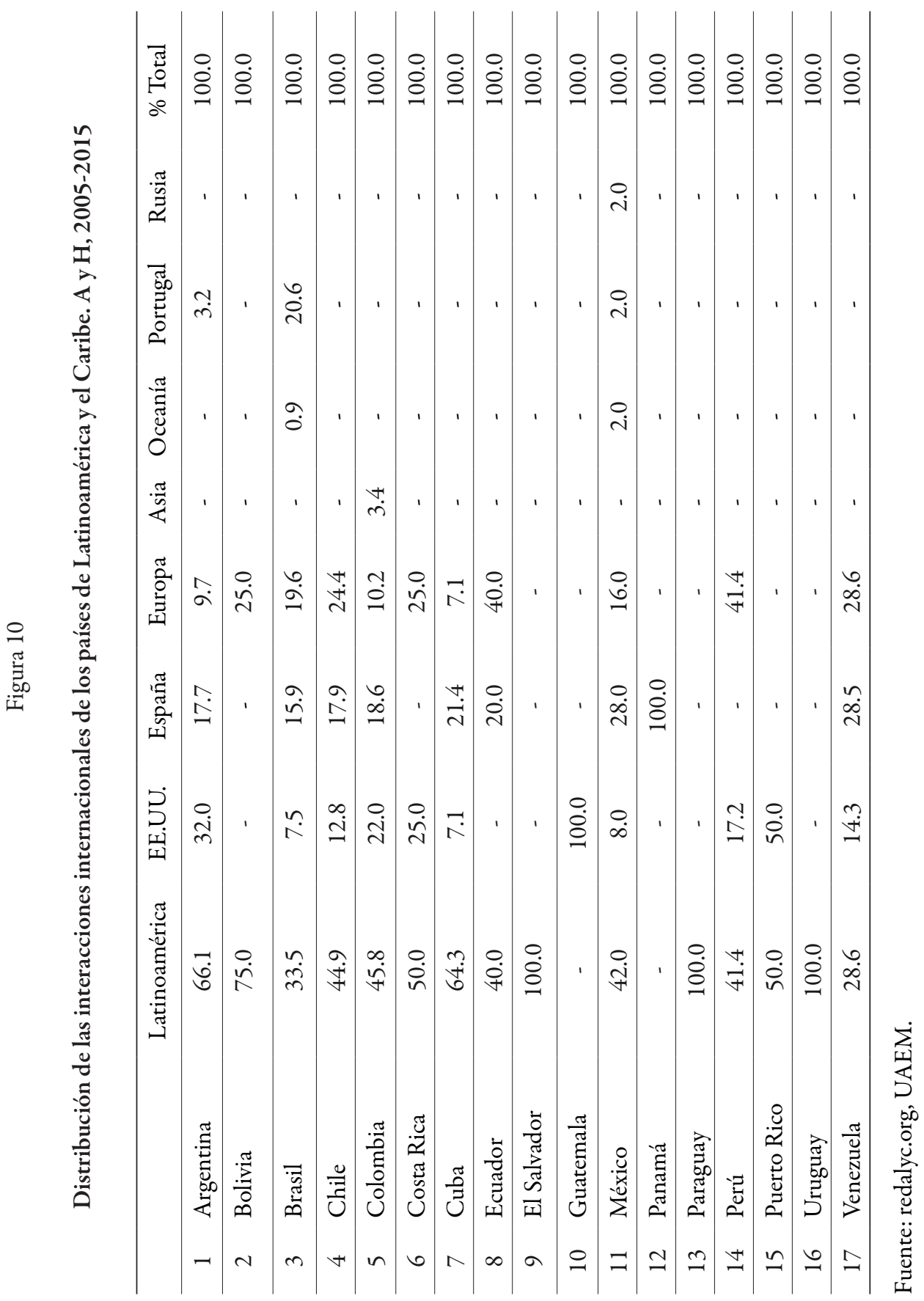


Eduardo Aguado-López. Doctor en Enseñanza superior por el CIDHEM, mexicano. Profesor-investigador de la Facultad de Ciencias Políticas y Sociales de la Universidad Autónoma del Estado de México. Líneas de investigación: comunicación científica, sociología de la ciencia, acceso abierto, epistemología. Publicaciones recientes: Aguado-López, Eduardo y Becerril-García, Arianna, “¿Publicar o perecer? El caso de las ciencias sociales y las humanidades en Latinoamérica”, en Revista Española de Documentación Cientifica, vol. 39, núm. 4, España: Consejo Superior de Investigaciones Científicas (2016); Aguado-López, Eduardo y Esther Juliana Vargas Arbeláez, "Reapropiación del conocimiento y descolonización: el acceso abierto como proceso de acción política del sur" en Revista Colombiana de Sociología. vol. 39, núm. 2. Bogotá: Universidad Nacional de Colombia (2016); Aguado-López, Eduardo y Becerril-García, Arianna; Aguilar Bustamante, Maria Constanza, "Universitas Psychologica: un camino hacia la internacionalización”, en Universitas Psychologica, vol.15, núm. 2. Colombia: Pontificia Universidad Javeriana (2016).

Arianna Becerril-García. Doctora en Ciencias de la Computación por el Tecnológico de Monterrey, mexicana. Profesora-investigadora de la Facultad de Ciencias Políticas y Sociales de la Universidad Autónoma del Estado de México. Líneas de investigación: web semántica, acceso abierto, tecnologías de la información. Publicaciones recientes: Aguado-López, Eduardo y Becerril-García, Arianna, “¿Publicar o perecer? El caso de las ciencias sociales y las humanidades en Latinoamérica”, en Revista Española de Documentación Cientifica, vol. 39, núm. 4, España: Consejo Superior de Investigaciones Científicas (2016); Becerril-García, Arianna; Lozano Espinosa, Rafael; y Molina Espinosa, José Martín, "Enfoque semántico para el descubrimiento de recursos sensible al contexto sobre contenidos académicos estructurados con OAI-PMH", en Computación y Sistemas, vol. 20, núm. 1, México: IPN (2016); Aguado-López, Eduardo y Becerril-García, Arianna; Aguilar Bustamante, Maria Constanza, "Universitas Psychologica: un camino hacia la internacionalización”, en Universitas Psychologica, vol. 15, núm. 2, Colombia: Pontificia Universidad Javeriana (2016).

Sheila Godínez-Larios. Licenciada en Ciencias Políticas y Administración Pública por la Universidad Autónoma del Estado de México, mexicana. Líneas de investigación: estudios sociales de la ciencia, acceso abierto.

Recepción: 7 de diciembre de 2016.

Aprobación: 20 de abril de 2017. 